\title{
Superficial and Deep Foveal Avascular Zone Area Measurement in Healthy Subjects Using Two Different Spectral Domain Optical Coherence Tomography Angiography Devices
}

\author{
Pasha Anvari, MD MPH; Amin Najafi, MD; Reza Mirshahi, MD; Mahsa Sardarinia, MD \\ Maryam Ashrafkhorasani, MD; Pegah Kazemi, BS; Gholamhoseyn Aghai, MD; Abbas Habibi, MD \\ Khalil Ghasemi Falavarjani, MD
}

Eye Research Center, The Five Senses Institute, Rassoul Akram Hospital, Iran University of Medical Sciences, Tehran, Iran

ORCID:

Pasha Anvari: https://orcid.org/0000-0002-3765-4206

Khalil Ghasemi Falavarjani: https://orcid.org/0000-0001-5221-1844

\section{Abstract}

Purpose: To compare the area of the foveal avascular zone (FAZ) in the superficial and deep retinal layers using two different spectral-domain optical coherence tomography angiography (OCTA) devices.

Methods: A cross-sectional comparative study was conducted to obtain macular OCTA images from healthy subjects using Optovue RTVue XR Avanti (Optovue, Inc, Fremont, CA) and Spectralis HRA+OCTA (Heidelberg Engineering, Heidelberg, Germany). Two independent trained graders measured the FAZ area using automated slab segmentation. The FAZ area in the superficial and deep retinal layers were compared.

Results: Twenty-three eyes of 23 subjects were included. The graders agreement was excellent $(>0.86)$ for all measurements. The mean FAZ area was significantly larger at the superficial retinal layer as compared to the deep retinal layer on both devices $\left(0.31 \pm 0.08 \mathrm{~mm}^{2} \mathrm{vs} 0.26 \pm 0.08 \mathrm{~mm}^{2}\right.$ in Optovue and $0.55 \pm 0.16 \mathrm{~mm}^{2}$ vs $0.36 \pm 0.13 \mathrm{~mm}^{2}$ in Spectralis, both $P<0.001$ ). The mean FAZ area was significantly greater in the superficial and deep retinal layers using Spectralis as compared to Optovue measurements ( $P<0.001$ for both comparisons).

Conclusion: In contrast to previous reports, the FAZ area was larger in the superficial retina as compared to deep retinal layers using updated software versions. Measurements from different devices cannot be used interchangeably.

Keywords: Fovea Avascular Zone; Optical Coherence Tomography Angiography; Optovue; Spectraldomain; Spectralis

J Ophthalmic Vis Res 2020; 15 (4): 517-523

\section{Correspondence to:}

Khalil Ghasemi Falavarjani, MD. Eye Research Center, Rassoul Akram Hospital, Sattarkhan-Niaiesh St., Tehran, Iran.

Email: drghasemi@yahoo.com ghasemifalavarjani.k@iums.ac.ir

Received: 25-02-2020 Accepted: 20-07-2020

\section{Access this article online}

Website:

https://knepublishing.com/index.php/JOVR

DOI:

10.18502/jovr.v15i4.7791

\section{INTRODUCTION}

Foveal avascular zone (FAZ) is the vessel-free central part of the macula surrounded by a

This is an open access journal, and articles are distributed under the terms of the Creative Commons Attribution-NonCommercial-ShareAlike 4.0 License, which allows others to remix, tweak, and build upon the work non-commercially, as long as appropriate credit is given and the new creations are licensed under the identical terms.

How to cite this article: Anvari $P$ Najafi $A$, Mirshahi $R$ Sardarinia $M$ Ashrafkhorasani M, Kazemi P, Aghai G, Habibi A, Falavarjani KG. Superficial and Deep Foveal Avascular Zone Area Measurement in Healthy Subjects

Using Two Different Spectral Domain Optical Coherence Tomography

Angiography Devices. J Ophthalmic Vis Res 2020;15:517-523. 
continuous network of capillary plexus. FAZ integrity is vital for normal visual acuity. Some retinal pathologies including retinal vascular occlusions and diabetic retinopathy alter FAZ shape; therefore, FAZ metrics can serve as prognostic biomarkers for visual acuity. ${ }^{[1-5]}$ Prior to the advent of optical coherence tomography angiography (OCTA), the most extensively used tools for evaluation of FAZ were fluorescein angiography (FA) and indocyanine green angiography (ICGA). ${ }^{[6-8]}$ However, FA and ICGA are invasive procedures with side effects associated with intravenous administration of the dye. ${ }^{[9]}$ In addition, dye leakage from incompetent vessels may fade FAZ border in retinal pathologies, complicating FAZ assessment. OCTA is a noninvasive modality to evaluate retinal and choroidal vasculature that generates flow maps of retinal vasculature through discrimination of blood motion signals. $^{[10-13]}$

Multiple OCTA devices are commercially available with distinct built-in software, algorithms, and techniques for visualization of retinal and choroidal vasculature and layer segmentation. The reliability and reproducibility of images provided by each device and the inter-device correlations are of great importance in clinical decision-making and patients' follow-up. ${ }^{[14]}$ Although several studies have reported the size of FAZ in OCTA images, automated segmentations of retinal slabs in older versions has remained a source of measurement error. ${ }^{[15,16]}$

The aim of this study was to measure and compare the FAZ area at the superficial and deep retinal layers using two different OCTA devices with the updated software versions.

\section{METHODS}

This cross-sectional comparative case-series was approved by the Iran University Ethics Committee (No. IR.IUMS.REC 1396.32837). Informed consent was obtained and the tenets of the Declaration of Helsinki were followed.

In total 23 eyes of 23 healthy employees of Rassoul Akram Hospital, without any medical conditions or ocular abnormalities, were enrolled between June 2018 and December 2018. All volunteers underwent a complete ophthalmic examination including best-corrected visual acuity (BCVA), slit-lamp examination, and fundus examination. Subjects with abnormal or suspicious findings during the examination were excluded. The right eye was considered as the target eye for OCTA imaging. All images were obtained on the same day, between $8 \mathrm{am}$ and $11 \mathrm{am}$.

OCTA images were obtained using the Optovue RTVue XR Avanti $(3 \times 3 \mathrm{~mm}$ centered on the fovea, Software version 2017.1.0.15, Optovue, Inc., Fremont, CA) and Spectralis HRA+OCTA $\left(15^{\circ} \times\right.$ $10^{\circ}$ scan pattern, Software version 6.9, 2017, Heidelberg Engineering, Heidelberg, Germany). The Optovue device visualizes retinal vasculature using a split-spectrum amplitude decorrelation algorithm (SSADA). The Spectralis is based on a probability algorithm which determines the presence of motion in each pixel by full spectrum amplitude-decorrelation. ${ }^{[17]}$

For Optovue, images with a quality score of $<5$ were excluded, and imaging was repeated until acceptable quality was achieved. The superficial capillary plexus (SCP) en face image was segmented automatically with an inner boundary set at the internal limiting membrane (ILM) and an outer boundary set $9 \mu \mathrm{m}$ above the inner plexiform layer (IPL). The deep capillary plexus (DCP) en face image was segmented with an inner boundary 9 $\mu \mathrm{m}$ above the IPL and an outer boundary at $9 \mu \mathrm{m}$ below the outer plexiform layer (OPL).

In the Spectralis device, only images with $Q$ scores greater than 15 were included. The superficial vascular complex (SVC) was segmented automatically from ILM to $17 \mu \mathrm{m}$ above the bottom border of the IPL and the deep vascular complex (DVC) was bounded from $17 \mu \mathrm{m}$ above the lower border of the IPL to the bottom of the outer plexiform layer. OCTA images were imported into ImageJ software (public domain software, National Institutes of Health, Bethesda, Maryland, USA). The measurement scale was calibrated using the known dimensions of the image $(3 \times 3 \mathrm{~mm}$ for Optovue and 200 microns scale bar for Spectralis) and the FAZ boundary was outlined manually using freehand selection tools by two independent trained graders (PA and MS) in the superficial, deep, and the full retinal slabs.

Statistical data analysis was performed using the SPSS (version 17.0; SPSS Inc., Chicago, IL, USA). Intra-class correlation coefficient (ICC) between graders was calculated. The Shapiro-Wilk test was used to verify the normality of data. Paired $t$-test was used to compare mean values between two 
devices. The Bland-Altman plot was employed to assess the agreement between the two devices in measuring the FAZ area at different retinal layers. $P$-values $<0.05$ were considered significant.

\section{RESULTS}

Twenty-three eyes of 23 normal subjects including 14 females (60.9\%) and 9 males (39.1\%) with a mean age of $34.2 \pm 8.7$ (range 28-59) years were included. ICC was $0.87,0.88$, and 0.86 for the measurements at superficial, deep, and full retina slabs with the Optovue device and 0.92 , 0.86 , and 0.88 for the measurements with the Spectralis device, respectively. In view of the excellent agreement between the graders, the mean values for the two graders were used for subsequent analysis.

Table 1 compares the FAZ measurements at the superficial and deep retinal layers with the two devices. The mean FAZ area in the superficial retinal layer was $0.55 \pm 0.16 \mathrm{~mm}^{2}$ vs $0.31 \pm$ $0.08 \mathrm{~mm}^{2}$ in the Spectralis and Optovue devices, respectively (Figure $1, P<0.001$ ). Similarly, the mean FAZ area in the deep retinal layer was significantly greater in the Spectralis as compared to the Optovue images $\left(0.36 \pm 0.13 \mathrm{~mm}^{2}\right.$ vs 0.26 $\left.\pm 0.08 \mathrm{~mm}^{2}, P<0.001\right)$. The mean FAZ area of the full retina was also significantly larger with the Spectralis as compared to the Optovue device $\left(0.36 \pm 0.10 \mathrm{~mm}^{2}\right.$ vs. $\left.0.26 \pm 0.07 \mathrm{~mm}^{2}, P<0.001\right)$

With both devices, the mean FAZ area was significantly larger in the superficial retinal layer (both $P$-values $<0.001$, Figure 1). None of the eyes had smaller FAZ area in the superficial retina as compared to the deep retina.

Bland-Altman plots (Figure 2) demonstrated lack of agreement between the two devices measuring the FAZ area in superficial, deep, and full retinal slabs.

\section{DISCUSSION}

In this study, the FAZ measurements were significantly larger in the superficial retina as compared to deep retinal layers, and both measurements were significantly greater using the Spectralis as compared to the Optovue. The OCTA provides volumetric data for different retinal layers. Each commercially available OCTA device uses a distinct built-in software for image processing and retinal layer segmentation. The details of segmentation algorithms are proprietary to manufacturers and are not publicly available. Limited studies have reported the comparisons of measurements using different devices. ${ }^{[18]}$ The methodology and results are conflicting between these studies.

In the current study, the FAZ area was manually determined using the ImageJ in the images captured by two spectral domain devices, Spectralis and Optovue, after automated segmentation of superficial and deep retinal layers. An excellent agreement between the independent graders was observed for both devices. Consequently, manual calculation of the FAZ area was a reliable and valid method. This is consistent with the results of previous studies reporting FAZ measurements in a single device. $^{[12,17,19-25]}$

In our study, the mean FAZ area measured with Optovue was similar to previous studies (Table 2). ${ }^{[12,17,19-25]}$ However, Spectralis OCTA measurements were larger than previously reported values, particularly in the SVC. We believe that the discrepancy between our results and previous reports is a result of the recent software update and changes in segmentation reference lines. Previous versions of Spectralis segmented the SCP from the ILM to the outer boundary of IPL, and the DCP from the outer boundary of the IPL to the outer boundary of the OPL. In recent software upgrades, the slabs are segmented differently as mentioned in the Methods section. Similar to our study, Mihailovic et $\mathrm{al}^{[24]}$ showed that the FAZ area is larger in Spectralis images as compared to the Optovue device.

The mean FAZ area measured by Optovue was smaller than Spectralis for all measured capillary plexuses. Spaide et $\mathrm{al}^{[15]}$ indicated that none of the automated segmentations by three different OCTA devices (Cirrus 5000 [Carl Zeiss Meditec], RTVue XR Avanti [Optovue], and Triton DRI OCT [Topcon Medical Systems]) correlated with histological sections. Similarly, Magrath et $\mathrm{al}^{[20]}$ reported significant variability in FAZ measurements between Optovue and Zeiss Cirrus HD-OCT 5000 (Carl Zeiss Meditec) devices, possibly due to different slab segmentation and dissimilarities in image spatial resolution.

In contrast to previous reports, the mean FAZ area at the SCP was significantly larger than 
Superficial

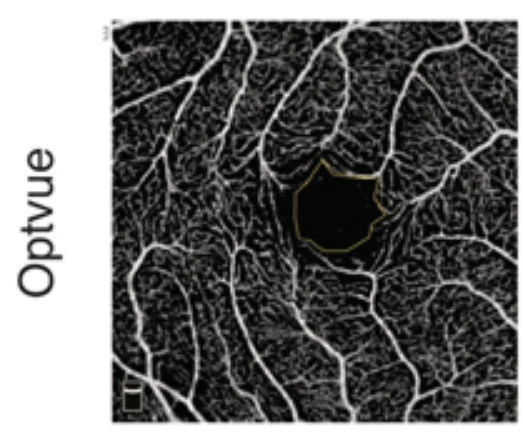

$0.30 \mathrm{~mm}^{2}$

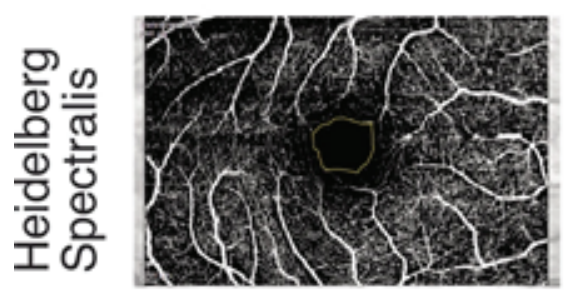

$0.47 \mathrm{~mm}^{2}$
Deep

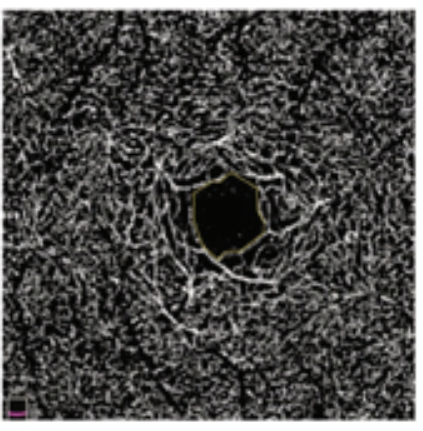

$0.24 \mathrm{~mm}^{2}$

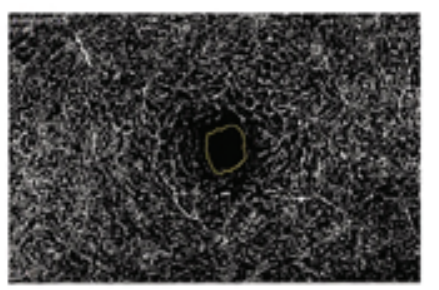

$0.26 \mathrm{~mm}^{2}$
Full Retina

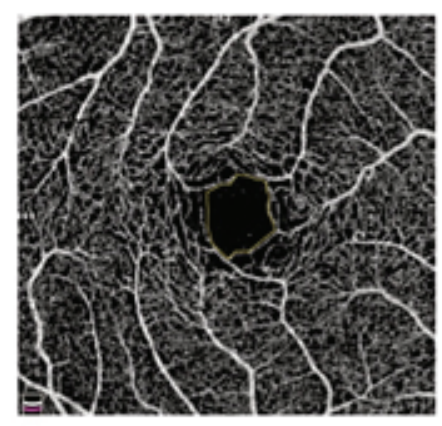

$0.24 \mathrm{~mm}^{2}$

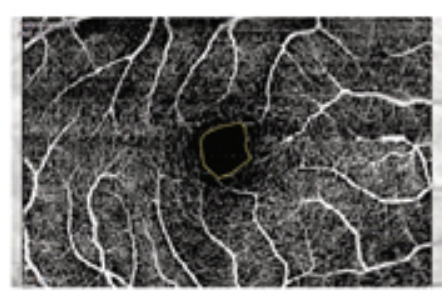

$0.26 \mathrm{~mm}^{2}$

Figure 1. Foveal avascular zone area measurements of one eye using Optovue and Heidelberg Spectralis devices at superficial, deep, and full retinal slabs.
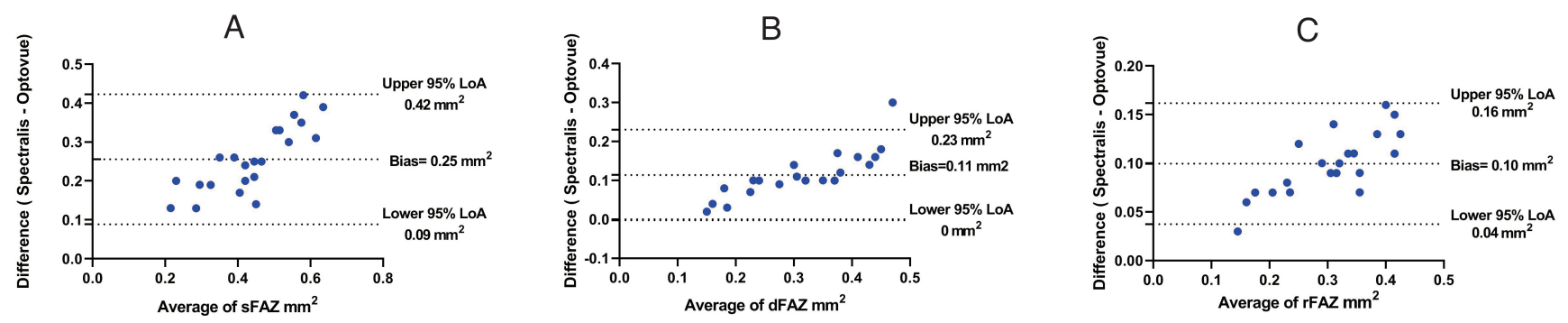

Figure 2. The Bland-Altman plots showing lack of agreement between Spectralis and Optovue devices in measuring FAZ area at A) superficial, B) deep and C) full retinal slabs.

sFAZ, superficial foveal avascular zone; dFAZ, deep foveal avascular zone; rFAZ, foveal avascular zone in full retinal slab; LoA, Limit of Agreement

the DCP in the current study. OCTA instruments only approximately measure the SCP and DCP in lieu of the four established capillary plexuses on histological examinations, ${ }^{[17]}$ and current limitations of spatial resolution of different OCTA instruments may explain the observed discrepancies. Rommel et $\mathrm{al}^{[16]}$ revealed that the FAZ area may be different in manual segmentation of retinal layers as compared to those obtained with automated segmentations. They found that in Canon device, the mean FAZ area was greater at the SCP than DCP on manual slab segmentation simulating histologic sections. ${ }^{[16]}$ We used the updated versions of the Optovue and Spectralis (Figure 3), the new segmentation algorithms may be closer to histologic descriptions of retinal capillary plexuses, as described by Spaides et al. ${ }^{[15]}$

Our study showed the importance of taking into account the instrument type as well as the software version in assessing quantitative metrics obtained from OCTA devices. This is particularly important when assessing the progression of a disease or response to an intervention using the $F A Z$ area on OCTA images.

We demonstrated the lack of agreement between Spectralis and Optovue in assessing 
Table 1. Comparison of the mean foveal avascular zone area at different capillary plexuses between the Spectralis and Optovue devices

\begin{tabular}{lccc}
\hline Slab & Optovue & Spectralis & P-value* \\
\hline Superficial capillary plexus $\left(\mathrm{mm}^{2}\right)$ & $0.31 \pm 0.08$ & $0.55 \pm 0.16$ & $P<0.001$ \\
Deep capillary plexus $\left(\mathrm{mm}^{2}\right)$ & $0.26 \pm 0.08$ & $0.36 \pm 0.13$ & $P<0.001$ \\
Full retina $\left(\mathrm{mm}^{2}\right)$ & $0.26 \pm 0.07$ & $0.36 \pm 0.10$ & $P<0.001$
\end{tabular}

*Paired $t$-test

Table 2. Foveal avascular zone area measured in previous studies using Optovue or Spectralis devices

\begin{tabular}{|c|c|c|c|c|}
\hline Authors & Superficial $\left(\mathrm{mm}^{2}\right)$ & Deep $\left(\mathrm{mm}^{2}\right)$ & Subjects & OCTA device \\
\hline Shahlaee et al, $2015^{[12]}$ & $0.27 \pm 0.101$ & $0.34 \pm 0.116$ & 17 healthy subjects & $\begin{array}{c}\text { Optovue, version } \\
2014.2 .0 .93\end{array}$ \\
\hline Samara et al, $2015^{[19]}$ & $0.266 \pm 0.097$ & $0.495 \pm 0.227$ & $\begin{array}{l}70 \text { eyes from } 67 \\
\text { healthy subjects }\end{array}$ & $\begin{array}{c}\text { Optovue, version } \\
\text { 2014.2.0.13 }\end{array}$ \\
\hline Magrath et al, 2016 ${ }^{[20]}$ & 0.2855 & 0.3465 & $\begin{array}{c}50 \text { eyes in } 25 \\
\text { healthy volunteers }\end{array}$ & $\begin{array}{l}\text { Optovue, } \\
\text { 2014.2.0.65 }\end{array}$ \\
\hline Pilotto et al, $2018^{[21]}$ & $0.30 \pm 0.08$ & $0.35 \pm 0.08$ & 59 normal eyes & $\begin{array}{l}\text { Spectralis } \\
\text { unspecified } \\
\text { version }\end{array}$ \\
\hline Coscas et al, 2016 ${ }^{[22]}$ & $0.28 \pm 0.1$ & $0.37 \pm 0.12$ & $\begin{array}{c}135 \text { eyes of } 70 \\
\text { subjects }\end{array}$ & $\begin{array}{c}\text { Optovue, version } \\
2015.100 .0 .35\end{array}$ \\
\hline Ghassemi et al, $2017^{[23]}$ & 0.27 & 0.35 & $\begin{array}{c}224 \text { eyes of } 112 \\
\text { volunteers }\end{array}$ & $\begin{array}{l}\text { Optovue, version } \\
\text { 2016.1.0.23-beta }\end{array}$ \\
\hline Corvi et al, $2017^{[17]}$ & $\begin{array}{c}\text { Spectralis: } 0.2408 \\
\text { Optovue: } 0.2211\end{array}$ & $\begin{array}{l}\text { Spectralis: } 0.3178 \\
\text { Optovue: } 0.2619\end{array}$ & 36 eyes & $\begin{array}{l}\text { Optovue, version } \\
\text { 2016.1.0.2 } \\
\text { Spectralis, version } \\
\text { SP 6.7a }\end{array}$ \\
\hline Mihailovic et al, $2018^{[24]}$ & 0.329 & 0.335 & 24 normal eyes & $\begin{array}{l}\text { Spectralis, } \\
\text { unspecified } \\
\text { version }\end{array}$ \\
\hline Falavarjani et al, 2018 & $0.32 \pm 0.11$ & $0.50 \pm 0.13$ & $\begin{array}{c}70 \text { eyes of } 70 \\
\text { healthy subjects }\end{array}$ & $\begin{array}{c}\text { Optovue, version } \\
\text { 2016.1.0.26 }\end{array}$ \\
\hline
\end{tabular}

FAZ area at different retinal layers. The average bias was larger when evaluating FAZ in the superficial retinal layers. Similarly, Mihailovic and colleagues ${ }^{[24]}$ showed slight but significant differences among Canon, Heidelberg, and Optovue in measuring the FAZ area.

One of the limitations of this study was relatively small sample size. Restricting the investigation to just two OCTA devices was another limitation. Larger studies are required to establish the relationship between FAZ measurements using different OCTA devices. In addition, the segmentation algorithm was different in the two devices. Further studies are warranted to demonstrate the repeatability of the measurements after manually changing segmentation boundaries to make them similar in different devices.
In conclusion, OCTA measurements are reliable for evaluation of FAZ area in various retinal slabs, however, commercially available devices may yield different values depending on their segmentation algorithms. Therefore, caution should be exercised in comparing measurements acquired by different OCTA devices.

\section{Financial Support and Sponsorship}

Nil.

\section{Conflicts of Interest}

There are no conflicts of interest. 


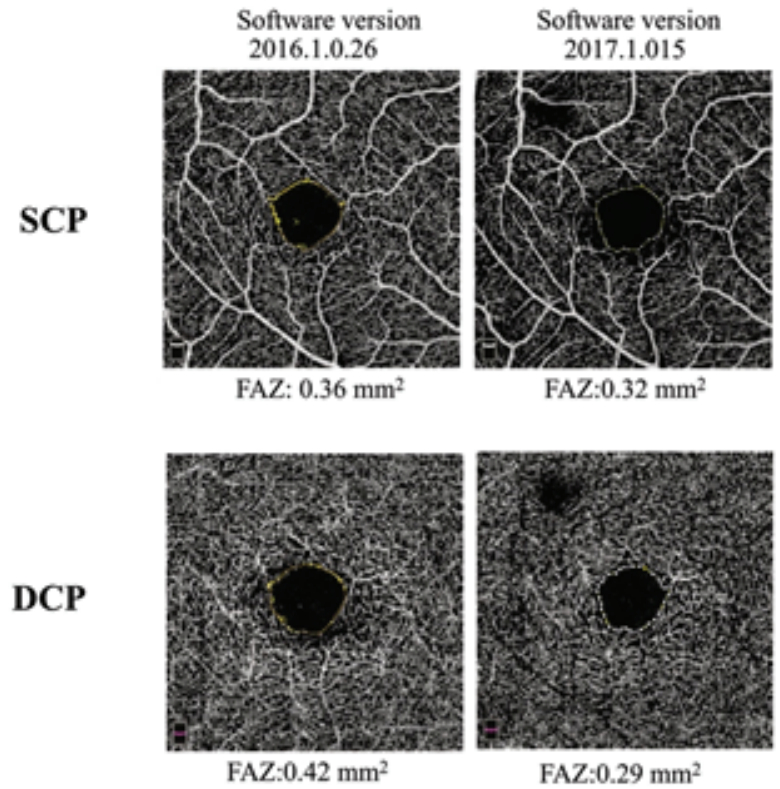

Figure 3. Comparison of foveal vascular zone area of one eye using two different software versions of the Optovue device. SCP, superficial capillary plexus; DCP, deep capillary plexus

\section{REFERENCES}

1. Minnella AM, Savastano MC, Federici M, Falsini B, Caporossi A. Superficial and deep vascular structure of the retina in diabetic macular ischaemia: OCT angiography. Acta Ophthalmol 2016;96:e647-e648.

2. Balaratnasingam C, Inoue M, Ahn S, McCann J, DhramiGavazi E, Yannuzzi LA, et al. Visual acuity is correlated with the area of the foveal avascular zone in diabetic retinopathy and retinal vein occlusion. Ophthalmology 2016;123:2352-2367. Retrieved from: https://doi.org/10. 1016/j.ophtha.2016.07.008.

3. Takase N, Nozaki M, Kato A, Ozeki H, Yoshida M, Ogura Y. Enlargement of foveal avascular zone in diabetic eyes evaluated by en face optical coherence tomography angiography. Retina 2015;35:2377-2383. Retrieved from: https://doi.org/10.1097//AE.0000000000000849.

4. De Salles MC, Kvanta A, Amrén U, Epstein D. Optical coherence tomography angiography in central retinal vein occlusion: correlation between the foveal avascular zone and visual acuity. Investig Ophthalmol Vis Sci 2016;57:OCT242-OCT246. Retrieved from: https://doi. org/10.1167/iovs.15-18819.

5. Khadamy J, Abri Aghdam K, Falavarjani KG. An update on optical coherence tomography angiography in diabetic retinopathy. J Ophthalmic Vis Res 2018;13:487-497. Retrieved from: https://doi.org/10.4103/jovr.jovr_57_18.

6. Kotsolis Al, Killian FA, Ladas ID, Yannuzzi LA. Fluorescein angiography and optical coherence tomography concordance for choroidal neovascularisation in multifocal choroidtis. Br J Ophthalmol 2010;94:1506-1508. Retrieved from: https://doi.org/10.1136/bjo.2009.159913.

7. Novotny HR, Alvis DL. A method of photographing fluorescence in circulating blood in the human retina. Circulation 1961;24:82-86.
8. Stanga PE, Lim JI, Hamilton P. Indocyanine green angiography in chorioretinal diseases: indications and interpretation: an evidence-based update. Ophthalmology 2003;110:15-21. Retrieved from: https://doi.org/10.1016/ S0161-6420(02)01563-4.

9. Musa F, Muen WJ, Hancock R, Clark D. Adverse effects of fluorescein angiography in hypertensive and elderly patients. Acta Ophthalmol Scand 2006;84:740742. Retrieved from: https://doi.org/10.1111/j.1600-0420. 2006.00728.x.

10. Spaide RF, Klancnik JM, Cooney MJ. Retinal vascular layers imaged by fluorescein angiography and optical coherence tomography angiography. JAMA Ophthalmol 2015;133:45. Retrieved from: https://doi.org/10.1001/jamaophthalmol.2014.3616.

11. Kashani $\mathrm{AH}$, Chen $\mathrm{CL}$, Gahm JK, Zheng F, Richter GM, Rosenfeld PJ, et al. Optical coherence tomography angiography: a comprehensive review of current methods and clinical applications. Prog Retin Eye Res 2017;60:66100. Retrieved from: https://doi.org/10.1016/j.preteyeres. 2017.07.002.

12. Shahlaee A, Pefkianaki M, Hsu J, Ho AC. Measurement of foveal avascular zone dimensions and its reliability in healthy eyes using optical coherence tomography angiography. $A m \mathrm{~J}$ Ophthalmol 2016;161:50-55e1. Retrieved from: https://doi.org/10.1016/j.ajo.2015.09.026.

13. Falavarjani KG. Optical coherence tomography angiography of the retina and choroid; current applications and future directions. J Curr Ophthalmol 2017;29:1-4.

14. Carpineto P, Mastropasqua R, Marchini G, Toto L, Di Nicola M, Di Antonio L. Reproducibility and repeatability of foveal avascular zone measurements in healthy subjects by optical coherence tomography angiography. $\mathrm{Br} \mathrm{J}$ Ophthalmo/ 2016;100:671-676. Retrieved from: https://doi. org/10.1136/bjophthalmol-2015-307330. 
15. Spaide RF, Curcio CA. Evaluation of segmentation of the superficial and deep vascular layers of the retina by optical coherence tomography angiography instruments in normal eyes. JAMA Ophthalmol 2017;135:259-262. Retrieved from: https://doi.org/10.1001/jamaophthalmol.2016.5327.

16. Rommel F, Siegfried F, Kurz M, Brinkmann MP, Rothe $M$, Rudolf $M$, et al. Impact of correct anatomical slab segmentation on foveal avascular zone measurements by optical coherence tomography angiography in healthy adults. J Curr Ophthalmol 2018;30:156-160. Retrieved from: https://doi.org/10.1016/j.joco.2018.02.001.

17. Corvi F, Pellegrini M, Erba S, Cozzi M, Staurenghi G, Giani A. Reproducibility of vessel density, fractal dimension, and foveal avascular zone using 7 different optical coherence tomography angiography devices. Am J Ophthalmol 2018;186:25-31. Retrieved from: https://doi.org/10.1016/j. ajo.2017.11.011.

18. Al-Sheikh M, Falavarjani KG, Tepelus TC, Sadda SR. Quantitative comparison of swept-source and spectral-domain OCT angiography in healthy eyes. Ophthalmic Surg Lasers Imag Retin 2017;48:385-391. Retrieved from: https://doi.org/10.3928/2325816020170428-04.

19. Samara WA, Say EAT, Khoo CTL, Higgins TP, Magrath G, Ferenczy S, et al. Correlation of foveal avascular zone size with foveal morphology in normal eyes using optical coherence tomography angiography. Retina 2015;35:2188-2195. Retrieved from: https://doi.org/10. 1097/IAE.0000000000000847.

20. Magrath GN, Say EAT, Sioufi K, Ferenczy S, Samara WA, Shields CL. Variability in foveal avascular zone and capillary density using optical coherence tomography angiography machines in healthy eyes. Retina 2017;37:2102-2111.
21. Pilotto E, Frizziero L, Crepaldi A, Della Dora E, Deganello $D$, Longhin $E$, et al. Repeatability and reproducibility of foveal avascular zone area measurement on normal eyes by different optical coherence tomography angiography instruments. Ophthalmic Res 2018;58:4847. Retrieved from: https://doi.org/10.1159/000485463.

22. Coscas F, Sellam A, Glacet-Bernard A, Jung C, Goudot $M$, Miere $A$, et al. Normative data for vascular density in superficial and deep capillary plexuses of healthy adults assessed by optical coherence tomography angiography. Investig Ophthalmol Vis Sci 2016;57:OCT211-223. Retrieved from: https://doi.org/10.1167/iovs.15-18793.

23. Ghassemi F, Fadakar K, Bazvand F, Mirshahi R, Mohebbi $M$, Sabour $S$. The quantitative measurements of vascular density and flow areas of macula using optical coherence tomography angiography in normal volunteers. Ophthalmic Surg Lasers Imag Retin 2017;48:478-486.

24. Mihailovic N, Brand C, Lahme L, Schubert F, Bormann E, Eter N, et al. Repeatability, reproducibility and agreement of foveal avascular zone measurements using three different optical coherence tomography angiography devices. PLoS One 2018;13:e0206045. Retrieved from: https://doi.org/10.1371/journal.pone.0206045.

25. Falavarjani K, Shenazandi H, Naseri D, Anvari P, Kazemi P, Aghamohammadi F, et al. Foveal avascular zone and vessel density in healthy subjects: An optical coherence tomography angiography study. J Ophthalmic Vis Res 2018;13:260. Retrieved from: https://doi.org/10.4103/jovr. jovr_173_17.

26. Falavarjani KG, Shenazandi H, Naseri D, Anvari P, Kazemi P, Aghamohammadi F, et al. Foveal avascular zone and vessel density in healthy subjects: an optical coherence tomography angiography study. J Ophthalmic Vis Res 2018:13:260-265. Retrieved from: https://doi.org/10.4103/ jovr.jovr_173_17. 